\title{
Positive effects of a healthy snack (fruit) versus an unhealthy snack (chocolate/crisps) on subjective reports of mental and physical health: a preliminary intervention study
}

\section{Andrew Paul Smith* and Rosannagh Rogers}

School of Psychology, Cardiff University, Cardiff, UK

\section{Edited by:}

Adrian Meule, University of

Wuerzburg, Germany

Reviewed by:

Tamlin Conner, University of Otago,

New Zealand

Anitra C. Carr, University of Otago,

New Zealand

*Correspondence:

Andrew Paul Smith, School of

Psychology, Cardiff University, 63 Park

Place, Cardiff CF10 3AS, UK

e-mail:smithap@cardiff.ac.uk
Background/Aims: Recent research has shown associations between type of snack and wellbeing. These studies have been cross-sectional and the aim of the present research was to examine this topic using an intervention study.

Methods: A between-subjects intervention study was carried out. Volunteers (100 students, mean age $=19.00$ years; 27 male, 73 female) completed online questionnaires measuring anxiety and depression, fatigue, somatic symptoms, cognitive difficulties, and distress at baseline. They were then randomly assigned to one of two snacking conditions chocolate/crisps or fruit. Volunteers consumed one snack item in the mid-afternoon each day for 10 days. At the end of the intervention, the volunteers completed the questionnaires again.

Results: Analyses of the baseline data confirmed that consumption of chocolate was associated with greater emotional eating and depression. Analyses of covariance, with the baseline data as covariates, were carried out on the post-intervention responses. The results showed that consumption of fruit was associated with lower anxiety, depression, and emotional distress than consumption of crisps/chocolate. Similarly, scores for somatic symptoms, cognitive difficulties, and fatigue were greater in the crisps/chocolate condition.

Conclusion: These results extend findings from cross-sectional studies and give a clearer indication of causal effects of different types of snacks on wellbeing.

Keywords: snacks, wellbeing, fruit, chocolate, crisps, depression, cognitive difficulties

\section{INTRODUCTION}

The study described in this article is part of our program of research on snacking and behavior. The research started by collecting data on the definition of snacking. One definition of snacking refers to eating a light meal or eating between meals. Our research has shown that eating several smaller meals at frequent intervals ("grazing") is associated with better cognitive performance and mood than eating fewer and larger meals at longer intervals (1). A more usual definition of snacking refers to eating and drinking between meals (2). Our research has extensively investigated effects of beverages consumed between meals [see Ref. (3-5)]. Knowledge of the effects of snack foods is more restricted and our recent studies have aimed to rectify this.

Studies of the acute effects of snacks have shown similar effects to those observed after meals [e.g., effects of cereal bars are similar to those of breakfast - $(6,7)]$. Smith (8) used methodologies developed in studies of meals on behavior to assess effects of regular patterns of snacking. These analyses showed little effect of snacking in general and this reflected the opposite effects of different kinds of snacks (9). The clearest example of this was found in a study of over 800 nurses (10). In this study, snacking on crisps, chocolate, and biscuits was associated with higher stress, more cognitive failures, and more injuries outside of work.

Many of the studies investigating effects of snacking have been cross-sectional. This means that it is unclear whether snacking changes mental health, or whether a person's mental health influences their eating behavior. Research has repeatedly demonstrated that the experience of negative emotions such as sadness and stress, results in increased food consumption (emotional eating) and increased amount of unhealthy content $(11,12)$. A range of empirical evidence has provided strong support for the relationship between emotional state and eating. For example, controlled laboratory-based studies of stress induced eating $(13,14)$, selfreport questionnaires (15), large population studies with children (16), and studies investigating the effects of naturally occurring stressful events such as examinations (17), have all provided strong support for the relationship between emotional eating traits and food consumption. Consumption of chocolate has often been related to emotional eating $(18,19)$. However, the debate about causality often applies to chocolate consumption. Correlations have been found between higher levels of depression in those who rely on chocolate to increase their moods (20), people who 
crave chocolate more (21), and those who label themselves as "chocolate addicts" (22). However, it is unclear whether those who are depressed eat more chocolate (emotional eating), or whether chocolate consumption is playing a role in maintaining or causing mental health problems. Both views have some support. For example, Parker and colleagues acknowledged that there are positive feelings experienced after eating chocolate in response to emotional eating; however, they also state that it is more likely that chocolate actually prolongs feelings of dysphoria (19). Emotional eating is not restricted to chocolate. For example, in a diary study Steptoe et al. (23) found more alcohol and fast food was consumed in high stress weeks.

There is also considerable support for the other causal pathway, namely that diet can influence mental health. Much of this research also involves cross-sectional studies. For example, a large number of correlational studies show that regular consumption of breakfast is associated with higher wellbeing scores [see Ref. (4, 24) for reviews]. These early results have been followed by intervention studies [e.g., Ref. $(25,26)]$, which have confirmed that consumption of breakfast is associated with greater wellbeing.

Research has also investigated other aspects of healthy eating, for example, consumption of fruit and vegetables. Results from large cross-sectional surveys show an association between positive aspects of wellbeing (life satisfaction and happiness) and greater consumption of fruit and vegetables (27). A recent daily diary study (28) has shown greater positive effect on days when more affect servings of fruit and vegetables were consumed. Results of lagged analysis showed that consumption of fruit/vegetables predicted increased wellbeing the next day, which suggests that it was consumption of healthy foods that was driving reported health not the other way around. Interventions have also examined effects of specific fruit (e.g., gold kiwifruit, a high vitamin $C$ food) on $\operatorname{mood}(29)$.

The purpose of the present study was to conduct an intervention study comparing consumption of unhealthy (chocolate/crisps) and healthy (fruit) snacks on subjective reports of mental and physical health. It followed the approach adopted in our breakfast research and used a 10-day intervention period. This duration is short enough to maintain compliance and has also been shown to be sensitive to dietary interventions [e.g., effects of fiber - (25)]. At baseline, correlations were computed to try to replicate previous results on associations between consumption of different snack types and subjective reports of health. The Dutch Eating Behavior Questionnaire (DEBQ) (30) was also administered at baseline to examine associations between emotional eating and consumption of different types of snacks. Following baseline, the snacking intervention was carried out for 10 days and further measures of subjective health taken at the end of this period.

\section{MATERIALS AND METHODS}

The study received approval from the School of Psychology ethics committee and was carried out with the informed consent of the participants.

\section{DESIGN}

A between-subjects design involving baseline measurements followed by a 10-day intervention was used. Cross-sectional data allowed investigation of associations between frequency of consuming different snacks, eating behavior and reports of physical and mental health. The intervention examined causal relationships between the health outcomes and snacking behavior. At enrollment, participants were given a number from 1 to 100 . A random number generator selected 50 numbers from 1 to 100 and these participants were assigned to one condition and those participant numbers not selected assigned to the other. The dependent variables measured were anxiety, depression, emotional distress, somatic symptoms, fatigue, and cognitive difficulty (see below).

\section{PARTICIPANTS}

\section{Sample size calculation}

Previous studies using this methodology have demonstrated effects of about $0.6 \mathrm{SD}$. With power set to 0.8 , $p$ set to 0.05 , a sample size of 44 per group was required.

One hundred undergraduate psychology students (mean age $=19$ years $\mathrm{SD}=0.79:$ male $=27$, female $=73 ; 98 \%$ white) completed this study. Participants were recruited from the School of Psychology Human Participant Panel and received course credits in exchange for participation.

\section{Materials}

Subjective reports of snack consumption, eating behavior, and health were measured using questionnaires presented on Survey Tracker. Survey Tracker exported all data straight into SPSS. Habitual consumption of chocolate (bars per week), crisps (bags per week), and fruit (pieces per week) were assessed at baseline. Subjective health was measured using the profile of fatigue related symptoms [PFRS; measures emotional distress, fatigue, somatic symptoms, and cognitive difficulties - (31)] and the hospital anxiety and depression scale [HADS; measures anxiety and depression - (32)]. Eating behavior was measured using the DEBQ (30). The main interest in the DEBQ was the emotional eating scale and only these data are reported here.

\section{Snacks}

In the fruit condition, participants were given 10 pieces of fruit (4 golden delicious apples, 3 large clementines, and 3 bananas) and told to consume 1 piece each afternoon for 10 days. In the chocolate/crisps condition, volunteers were given 10 snacks (5 packets of assorted crisps and 5 chunky chocolate wafers). Snacks were chosen on the basis that chocolate and crisps represent unhealthy snacking whereas fruit is associated with health snacking $(9,10,18)$.

\section{Procedure}

Participants then filled out the first online questionnaire (baseline measures), which took $8 \mathrm{~min}$ and then were given their snacks. Written instructions informed participants to consume one provided snack once a day for 10 days, preferably in the afternoon as well as consume their normal diet. If participants were unable to store all of their snacks they took some and collected the rest during the 10-day period.

Participants were told that they would get a reminder email on the fifth day of the intervention, which gave details of when they would receive the second questionnaire and asked to email 
the experimenter if they were experiencing any problems with the study. On the ninth day, participants were sent the second questionnaire (secondary measures) and were told to complete it on the last day of the intervention (day 10) after they had consumed their last snack. When the baseline data and post-intervention data were merged the database was made anonymous, participants were credited for their participation, and debriefs were emailed to participants.

\section{STATISTICAL ANALYSIS}

Data analysis involved Pearson product moment correlations being computed for baseline measures of snacking frequency, wellbeing (PFRS; HADS) and eating behavior (DEBQ). This was to replicate previous results from cross-sectional studies. Analyses of covariance, with snacking condition as the between subject factor, were carried out on the post-intervention scores with the corresponding baseline score and emotional eating as covariates. Entering these factors into the statistical model allowed the analysis to assess if the intervention had a significant impact on wellbeing when controlling for emotional eating and baseline measures.

\section{RESULTS}

The two intervention groups did not differ on age, gender nor the baseline PFRS, HADS, or DEBQ variables (all $p$ 's > 0.05).

\section{CORRELATIONS BETWEEN BASELINE MEASURES}

Results revealed that emotional eating and depression correlated significantly with consumption of chocolate (Table 1). None of the other correlations were significant.

\section{RESULTS FOR THE INTERVENTION}

Analyses of covariance revealed that there were significant differences in subjective reports of health between the snacking conditions (see Table 2). The adjusted means demonstrate the effects of the intervention with those in the fruit condition reporting lower mental and physical health problems compared with those in the chocolate and crisps condition.

If one examines percentage change from baseline (Table 3 ) one finds that those in the chocolate/crisp condition reported large increases in depression, emotional distress, and fatigue. Other outcomes were lower than baseline in the chocolate/crisps condition but the reductions were significantly greater in the fruit condition.

Table 1 | Correlations between regular consumption of healthy/unhealthy snacks, subjective reports of health and emotional eating in the baseline data.

\begin{tabular}{lccr}
\hline & Chocolate & Crisps & Fruit \\
\hline Emotional distress & 0.14 & -0.06 & -0.08 \\
Fatigue & 0.13 & -0.06 & -0.10 \\
Cognitive difficulties & 0.08 & 0.05 & -0.14 \\
Somatic & 0.02 & 0.00 & -0.08 \\
Anxiety & -0.01 & -0.08 & 0.05 \\
Depression & $0.19^{*}$ & -0.09 & 0.00 \\
Emotional eating & $0.21^{*}$ & -0.08 & 0.05 \\
\hline
\end{tabular}

${ }^{*} p<0.05,1$-tail.

\section{DISCUSSION}

Recent reviews [e.g., Ref. $(33,34)$ ] and meta-analyses (35) highlight the need for further research on snacking and health. Despite many years of interest in the effects of snacking, there has been a lack of consistency in study design and definition of snacking. In addition, many of the studies have been cross-sectional and failed to provide control for potential confounders. There is evidence that snacking consisting of better diets (e.g., greater consumption of fruit and vegetables) is associated with better mental health (3538). Again, most of these studies have been cross-sectional, which makes it difficult to assign causality.

The results from the present intervention study support the view that consumption of fruit improves mental health compared to consumption of crisps/chocolate. Further research is required to determine the extent to which these effects generalize across other types of snack. Indeed, even within the category of fruit there may be variation depending on the micronutrient composition of the product. Similarly, it has been suggested that dark chocolate may have potential benefits due to anti-oxidant and phytochemical effects (39). However, results from a double blind placebo controlled study failed to demonstrate beneficial effects of dark chocolate (40).

The present study was intended to be an initial intervention and there were some limitations in the methodology. First, it would have been desirable to collect a more detailed dietary intake both at baseline and at the end of the intervention. Although participants were instructed to maintain their normal diet, it is possible that the effects reported here may reflect factors other than the intervention. It would also be useful to examine daily reports of mental and physical health in order to determine how rapidly effects of

\begin{tabular}{|c|c|c|c|}
\hline Measure & Fruit & $\begin{array}{l}\text { Chocolate/ } \\
\text { crisps }\end{array}$ & Significance \\
\hline Anxiety & $5.46(0.33)$ & $6.77(0.33)$ & $F(1,96)=7.95, p<0.05$ \\
\hline Depression & $2.40(0.25)$ & $3.32(0.25)$ & $F(1,96)=6.43, p<0.05$ \\
\hline Somatic & $28.10(1.36)$ & $33.82(1.36)$ & $F(1,96)=8.26, p<0.005$ \\
\hline Cognitive & $25.59(1.21)$ & $31.61(1.21)$ & $F(1,96)=11.44, p<0.001$ \\
\hline Fatigue & $27.83(1.36)$ & $34.21(1.36)$ & $F(1,96)=10.33, p<0.005$ \\
\hline $\begin{array}{l}\text { Emotional } \\
\text { distress }\end{array}$ & $36.89(1.70)$ & $46.57(1.70)$ & $F(1,96)=16.11, p<0.001$ \\
\hline
\end{tabular}

Table 3 | Percentage change from baseline in wellbeing scores for the different snacking condition.

\begin{tabular}{lcc}
\hline & Fruit (\%) & Chocolate/crisps (\%) \\
\hline Anxiety & -31.8 & -18.5 \\
Depression & -0.5 & +46.6 \\
Somatic & -21.7 & -7.0 \\
Cognitive & -15.0 & -0.3 \\
Fatigue & -8.7 & +10.6 \\
Emotional distress & -7.2 & +10.2
\end{tabular}


the intervention develop. Finally, it is important to include measures of positive affect and other aspects of wellbeing in future research.

The current study tells us little about the mechanisms underlying the effects of the different snacks on wellbeing. Two types of explanation can be distinguished. The first type of effect might focus on the nutrients provided by the different snacks. In contrast to this, it may be the cognitions associated with the different snacks that are important. This last view could be tested by giving volunteers identical snacks but labeling one as "unhealthy" and the other as "healthy."

In conclusion, the results from the present intervention study confirm and extend earlier cross-sectional research on the effects of different types of snack on subjective reports of health [e.g., Ref. (9)]. Mental health is important in its own right but it is also a major risk factor for chronic disease (41). Given that many mental health problems are initially apparent in adolescence and early adulthood (42), it is now important to examine whether common mental disorders can be prevented by simple dietary interventions.

\section{REFERENCES}

1. Hewlett P, Smith A, Lucas E. Grazing, cognitive performance and mood. Appetite (2009) 52:245-8. doi:10.1016/j.appet.2008.09.008

2. Chaplin K, Smith AP. Definitions of snacking. Curr Top Nutraceutical Res (2011) 9(1-2):53-9.

3. Smith AP. Effects of caffeine on human behaviour. Food Chem Toxicol (2002) 40:1243-55. doi:10.1016/S0278-6915(02)00096-0

4. Smith AP. Caffeine. In: Lieberman H, Kanarek R, Prasad C, editors. Nutritional Neuroscience. London: Taylor \& Francis (2005). p. 335-59.

5. Smith AP. Caffeine: practical implications. In: Kanarek RB, Lieberman HR, editors. Diet, Brain, and Behavior: Practical Implications. London: Taylor \& Francis (2011). p. 271-92.

6. Smith AP, Wilds A. The effects of cereal bars for breakfast and mid-morning snacks on mood and memory. Int J Food Sci Nutr (2009) 60(s4):63-9. doi:10.1080/09637480802438305

7. Smith AP, Stamatakis C. Cereal bars, mood and memory. Curr Top Nutraceutical Res (2010) 8(4):169-72. doi:10.1080/09637480802438305

8. Smith AP. Snacking frequency and well-being. Curr Top Nutraceutical Res (2011) 9(1-2):47-51.

9. Chaplin K, Smith AP. Snacking frequency, mental health, health beliefs and physical health. Curr Top Nutraceutical Res (2011) 9(1-2):41-5.

10. Chaplin K, Smith AP. Breakfast and snacks: associations with cognitive failures, minor injuries, accidents and stress. Nutrients (2011) 3:515-28. doi:10.3390/ nu3050515

11. Greeno CG, Wing RR. Stress-induced eating. Psychol Bull (1994) 115:444-64. doi:10.1037/0033-2909.115.3.444

12. Grunberg NE, Straub RO. The role of gender and taste class in the effects of stress on eating. Health Psychol (1992) 11:97-100. doi:10.1037/0278-6133.11.2.97

13. Zellner DA, Loaiza S, Gonzalez Z, Pita J, Morales J, Pecora D. Food selection changes under stress. Physiol Behav (2006) 87:789-93. doi:10.1016/j.physbeh. 2006.01.014

14. Oliver G, Wardle J, Gibson EL. Stress and food choice: a laboratory study. Psychosom Med (2000) 62:853-65. doi:10.1097/00006842-200011000-00016

15. Oliver G, Wardle J. Perceived effects of stress on food choice. Physiol Behav (1999) 66:511-5. doi:10.1016/S0031-9384(98)00322-9

16. Cartwright M, Wardle J, Steggles N, Simon AE, Croker H, Jarvis MJ. Stress and dietary practices in adolescents. Health Psychol (2003) 22:362-9. doi:10.1037/ 0278-6133.22.4.362

17. Macht M, Haupt C, Ellgring $H$. The perceived function of eating is changed during examination stress: a field study. Eat Behav (2005) 6:109-12. doi:10.1016/j. eatbeh.2004.09.001

18. Macht M, Mueller J. Immediate effects of chocolate on experimentally induced mood states. Appetite (2007) 49(3):667-74. doi:10.1016/j.appet.2007.05.004
19. Parker G, Parker I, Brotchie H. Mood state effects of chocolate. J Affect Disord (2006) 92:149-59. doi:10.1016/j.jad.2006.02.007

20. Schuman M, Gitlin MJ, Fairbanks L. Sweets chocolate and atypical depressive traits. J Nerv Ment Dis (1987) 175:491-5. doi:10.1097/00005053-19870800000008

21. Lester D, Bernard D. Liking for chocolate depression and suicidal preoccupation. Psychol Rep (1991) 69:570. doi:10.2466/PRO.69.6.570.570

22. Hetherington MM, MacDiarmid JI. Chocolate addiction: a preliminary study of its description and its relationship to problem eating. Appetite (1993) 21:233-46. doi:10.1006/appe.1993.1042

23. Steptoe A, Lipsey Z, Wardle J. Stress, hassles and variations in alcohol consumption, food choice and physical exercise: a diary study. Health Psychol (1998) 3:51-63. doi:10.1111/j.2044-8287.1998.tb00555.x

24. Smith AP. Breakfast and adult's and children's behavior. In: Kanarek RB, Lieberman HR, editors. Diet, Brain, and Behavior: Practical Implications. London: Taylor \& Francis (2011). p. 53-70.

25. Smith AP, Bazzoni C, Beale J, Elliott-Smith J, Tiley M. High fibre breakfast cereals reduce fatigue. Appetite (2001) 37:249-50. doi:10.1006/appe.2001.0428

26. Smith AP. An investigation of the effects of breakfast cereals on alertness, cognitive function and other aspects of the well-being of children. Nutr Neurosci (2010) 13(5):230-6. doi:10.1179/147683010X12611460764642

27. Blanchflower D, Oswald A, Stewart-Brown S. Is psychological well-being linked to the consumption of fruit and vegetables? Soc Indic Res (2013) 114:785-801. doi:10.1007/s11205-012-0173-y

28. White BA, Horwath CC, Conner TS. Many apples a day keep the blues awaydaily experiences of negative and positive affect and food consumption in young adults. Br J Health Psychol (2013) 18:782-98. doi:10.1111/bjhp.12021

29. Carr AC, Bozonet SM, Pullar JM, Vissers MCM. Mood improvement in young adult males following supplementation with gold kiwifruit, a high vitamin C food. J Nutr Sci (2013) 2(24):1-8. doi:10.1017/jns.2013.12

30. Van Strien T, Frijters JER, Bergers GPA, Defares PB. The Dutch Eating Behaviour Questionnaire (DEBQ) for assessment of restrained, emotional and external eating behaviour. Int J Eat Disord (1986) 5:295-315. doi:10.1002/1098108X(198602)5:2<295::AID-EAT2260050209>3.0.CO;2-T

31. Ray C, Weir WRC, Phillips C, Cullen S. Development of a measure of symptoms in chronic fatigue syndrome: the profile of fatigue related symptoms (PFRS). Psychol Health (1992) 7:27-43. doi:10.1080/08870449208404293

32. Zigmond AS, Snaith RP. HADS: hospital anxiety and depression scale. Acta Psychiatr Scand (1983) 67:361-70. doi:10.1111/j.1600-0447.1983.tb09716.x

33. Miller R, Benelam B, Stanner SA. Is snacking good or bad for health: an overview. Nutr Bull (2013) 38:302-22. doi:10.1111/nbu.12042

34. Rooney C, McKinley MC, Woodside JV. The potential role of fruit and vegetables in aspects of psychological wellbeing: a review of the literature and future directions. Proc Nutr Soc (2013) 72:420-32. doi:10.1017/ S0029665113003388

35. Lai JS, Hiles S, Bisquera A, Hure AJ, McEvoy M, Attia J. A systematic review and meta-analysis of dietary patterns and depression in community-dwelling adults. Am J Clin Nutr (2014) 99:181-97. doi:10.3945/ajcn.113.069880

36. Jacka FN, Kremer PJ, Berk M, de Silva-Sanigorski AM, Moodie M, Leslie ER, et al. A prospective study of diet and mental health in adolescents. PLoS One (2011) 6:e24805. doi:10.1371/journal.pone.0024805.t003

37. Oellingrath IM, Svendsen MV, Hestetun I. Eating patterns and mental health problems in early adolescence - a cross-sectional study of 12-13-year - old Norwegian schoolchildren. Public Health Nutr (2013) 10:1-9. doi:10.1017/ S1368980013002747

38. Sodergen M, McNaughton SA, Salmon J, Ball K, Crawford DA. Associations between fruit and vegetable intake, leisure-time physical activity, sitting time and self-rated health among older adults: cross-sectional data from the WELL study. BMC Public Health (2012) 2512:551. doi:10.1186/1471-245812-551

39. Martin FP, Rezzi S, Pere-Trepat E, Kamlage B, Collino S, Leibold E, et al. Metabolic effects of dark chocolate consumption of energy, gut microbiota, and stressrelated metabolism in free-living subjects. J Proteome Res (2009) 8:5568-79. doi:10.1021/pr900607v

40. Crews WD, Harrison DW, Wright JW. A double blind, placebo-controlled, randomiszed trial of the effects of dark chocolate and cocoa on variables associated with neuropsychological functioning and cardiovascular health: clinical findings from a sample of healthy, cognitively intact older adults. Am J Clin Nutr (2009) 87:872-80. 
41. Bhattacharya R, Shen C, Sambamoorthi U. Excess risk of chronic physical conditions associated with depression and anxiety. BMC Psychiatry (2014) 14:10. doi:10.1186/1471-244x-14-10

42. Patton G, Coffey C, Romanjuk H, Mackinnon A, Carlin JB, Degenhardt L, et al. The prognosis of common mental disorders in adolescents: a 14 year prospective cohort study. Lancet (2014) 383:1404-11. doi:10.1016/50140-6736(13)62116-9

Conflict of Interest Statement: The authors declare that the research was conducted in the absence of any commercial or financial relationships that could be construed as a potential conflict of interest.

Received: 03 April 2014; accepted: 01 July 2014; published online: 16 July 2014.
Citation: Smith AP and Rogers $R$ (2014) Positive effects of a healthy snack (fruit) versus an unhealthy snack (chocolate/crisps) on subjective reports of mental and physical health: a preliminary intervention study. Front. Nutr. 1:10. doi: 10.3389/fnut.2014.00010

This article was submitted to Eating Behavior, a section of the journal Frontiers in Nutrition.

Copyright (C) 2014 Smith and Rogers. This is an open-access article distributed under the terms of the Creative Commons Attribution License (CC BY). The use, distribution or reproduction in other forums is permitted, provided the original author $(s)$ or licensor are credited and that the original publication in this journal is cited, in accordance with accepted academic practice. No use, distribution or reproduction is permitted which does not comply with these terms. 